\title{
MENINOS E MOLEQUES: FACES DA INFÂNCIA EM CHOVE NOS CAMPOS DE CACHOEIRA
}

\author{
Ivone dos Santos Veloso ${ }^{1}$ \\ Marlí Tereza Furtado²
}

\begin{abstract}
RESUMO: O presente ensaio focaliza a figuração da infância e da criança no romance de estreia de Dalcídio Jurandir, Chove nos Campos de Cachoeira (1941). Assim, nossa análise se volta para os personagens mirins denominadas na narrativa de meninos e moleques, que a nosso ver encenam, dentro do universo infantil retratado nas passagens do livro, uma luta de classes entre os mais privilegiados socialmente e os desvalidos.

Palavras-chave: Infância. luta de classes. Dalcídio Jurandir
\end{abstract}

\begin{abstract}
Dalcídio Jurandir, Chove nos Campos de Cachoeira (1941). Thus, our analysis turns to the children's characters named in the narrative of boys and brats, who in our view enact, within the children's universe portrayed in the passages of the book, a class struggle between the most privileged socially and the underprivileged.
\end{abstract}

Key-words: Childhood. class struggle. Dalcídio Jurandir

\section{Brevíssima introdução}

O projeto literário de Dalcídio Jurandir (1909-1979) que ficou conhecido como Ciclo Extremo Norte se constitui de uma saga romanesca de dez romances iniciada com Chove nos Campos de Cachoeira (1941), e seguidos por Marajó (1947), Três casas e um rio (1958), Belém do Grão-Pará (1960), Passagem dos inocentes (1963), Primeira manhã (1967), Ponte do Galo (1971) Os Habitantes (1976), Chão dos Lobos (1976) e Ribanceira (1978). É sabido entre os estudiosos de sua obra que o fio de alinhavo do ciclo é Alfredo, que vai da meninice à idade adulta e aparece em todos as narrativas, com exceção de Marajó (1947), o romance- ilha ${ }^{3}$ dessa série.

Nesse painel construído pelo escritor marajoara, com o fim de dar visibilidade a sua "criaturada das barrancas" (JURANDIR:1992), gente pobre e desvalida que constituía o que ele mesmo chamou de "aristocracia de pé no chão" (JURANDIR:1992), o leitor prontamente encontrará imagens da infância, pois, embora Dalcídio Jurandir não objetivasse criar uma história da infância na Amazônia, seus romances frequentemente trazem à tona personagens infantis ou personagens que rememoram a infância, tais como: Alfredo, o menino do caroço de tucumã e de pernas feridentas; Missunga, "o menino branco com linguagem de negro" (SALLES:1992); Libânia, a menina-agregada da madrinha-mãe, Antônio, o menino roubado, e tantas outras figuras de moleques, andarilhos, ricos e pobres, crianças narradas e narradoras da cultura amazônica.

Partindo dessas primeiras indicações, cremos que a categoria infância é uma chave de leitura relevante para investir numa interpretação do Ciclo Extremo Norte, e que, sobretudo, é na representação de uma infância desvalida, revelada nas personagens, imagens, histórias e simbologias que vemos de maneira contundente a dimensão social do projeto literário dalcidiano.

Nesta oportunidade, vislumbramos o primeiro romance dalcidiano, atentando nosso olhar sobre o núcleo de personagens mirins, que a nosso ver encenam, dentro do universo infantil retratado nas passagens do livro, uma luta de classes entre os mais privilegiados socialmente e os desvalidos.

\footnotetext{
${ }^{1}$ Professora Adjunto I da Universidade Federal do Pará. E-mail: yvoneveloso@ gmail.com.

${ }^{2}$ Professora do Programa de Pós-Graduação em Letras, área de Estudos Literários, da Universidade Federal do Pará. Email: marlitf@ufpa.br.

${ }^{3} \mathrm{O}$ termo romance-ilha foi utilizado para caracterizar o aparente isolamento do romance no Ciclo Extremo-Norte.
} 


\section{Meninos e moleques nos campos de Cachoeira}

Chove nos campos de Cachoeira é o romance de estreia de Dalcídio Jurandir que recebeu notoriedade como romancista em 1941, quando, após participar do concurso organizado pelo jornal literário Dom Casmurro e pela Editora Vecchi, com o pseudônimo Jaguarajó, ganhou o primeiro lugar e obteve como prêmio a publicação do romance. Essa primeira narrativa foi chamada de romanceembrião pelo próprio romancista, visto que nele se encontram praticamente todos os motes que serviram de matéria para o desenvolvimento do seu projeto literário de recriar ficcionalmente a Amazônia, inclusive os motes da infância, que em Dalcídio Jurandir aparecem por meio das personagens infantis, ou personagens que rememoram a infância, da representação do imaginário da criança, e também da própria estruturação narrativa, através da incorporação e, muitas vezes, reelaboração de contos, de mitos, de lendas e de outros signos da cultura popular e erudita que se aproximam, de alguma forma, com o universo infantil.

No romance-embrião, portanto, há uma abundância de imagens de meninos e meninas que sequer tem nome, e, por vezes, sequer tem voz. Essas crianças, quase sempre inominadas pelo narrador e mudas na narrativa, se revelam diversas vezes debilitadas, marginalizadas e dependentes da caridade alheia para sobreviverem ao cotidiano de sua pobreza:

Eram amarelinhos, barrigudos e pedichões. D. Amélia dava purgantes, sobras de pano, conselho, carões, mas não podia acabar com a pobreza[...] os pequenos sabiam comer traíra inteira com espinha saindo pela boca, piróngos de farinha, cuiadas de chibé, terra, sabão, tabaco. Comiam a se fartar, quando havia, com uma fome crônica, tendo ataque de vermes, cabeludos e viciados. Alfredo não gostava desses moleques, com desdém, negava as coisas, via que eles eram como bichos" (JURANDIR: 1995, p.94)

A construção dessas figuras infantis reforça, por uma ótica, o desvalimento social desse grupo, e por outro, o fato de as situações vivenciadas serem comuns e compartilhadas entre várias personagens. Assim, dá-se ênfase, mais as condições miseráveis e desumanas em que se encontram, de maneira, que Alfredo os reconhece como animais e não seres humanos, ou ainda, em um nível abaixo:" Um moleque não tinha talvez o valor dum passarinho." (JURANDIR:1995, p.19)

O rendimento narrativo dessas personagens é também relevante para melhor caracterizar Alfredo como menino que, embora não reconheça o seu desvalimento e se veja diferente dos outros garotos de Cachoeira, consegue perceber os infortúnios que o rodeiam e dos quais ele quer fugir.

Assim, entre as crianças sem nome na narrativa sobressaem-se aquelas designadas como moleques, que mesmo não apresentando atributos étnicos, aproximam-se da cultura negra, a começar pela etimologia dessa denominação. A palavra moleque provém do termo "mu'leke", de origem no quimbundo e quer dizer, literalmente, menino, ou, como informa Miriam L. Moreira Leite, significava negrinho, passando, mais tarde a corresponder a "indivíduo sem palavra ou gravidade, canalha, patife, velhaco, ou apenas menino de pouca idade, ou ainda escravo jovem recém-chegado da África." (LEITE:1997, p. 22).

Nesse sentido, embora praticamente não haja referências de cor, essas personagens infantis se aproximam do status de inferioridade ao qual os negros foram relegados historicamente na sociedade brasileira, ao mesmo tempo, também podem denotar aqueles que são criados à solta, na rua: 'Um moleque espiou na porta, apanhou uma bagana e correu para o pequeno bosque do professor" (JURANDIR: 1995, p.46). Neste fragmento, além de notarmos a situação de rua do moleque, é exemplar a entrada e saída repentina dessa figura secundária na narrativa, que poderia até passar despercebida, mas o narrador insiste em reportar a sua presença, e mesmo que este não lhe dê voz e 
ele sequer apareça ligado ao núcleo da ação, o fato de sua presença aponta para a sua marginalidade social, lugar periférico dentro e fora da narrativa, do qual ele espreita e pode de súbito, literalmente, roubar a cena.

Dessa maneira, em diversos momentos o olhar do narrador se volta para esses garotos, observando suas brincadeiras, suas condições de moradia e de saúde, e suas dificuldades diárias, compondo, desse modo, um grande panorama a partir desses fragmentos de uma infância desvalida.

Em outro trecho a relação com a subjugação dos negros alcança maior destaque, quando o narrador revela o tratamento que Dr. Campos, Juiz da cidade de Cachoeira, dá ao seu moleque de casa:

\begin{abstract}
— Mas, ó verme, onde estavas? [...] O moleque estendia a cerveja ao Juiz. Dr. Campos põe primeiro as mãos nos quadris para contemplar e investir contra o moleque: Hem? Põe aí a cerveja. Não estás vendo a mesa? Não tem mais olhos, seu vagabundinho? Sempre na safadeza, peraltíssimo! Arrumo-te um livro... Não se retire, não se retire, antes que eu lhe diga tudo o que tenho de dizer. Já não lhe disse isto? Sempre quando falo tem de ouvir. Como é que só porque mandei por a cerveja na mesa já vai se escapulindo? Onde estava? hem? Que fazia, que demorou tanto? Salu, nada! Salu, Salu é a sua vagabundagem, é a sua vadiação. Patife... Arrumo-te um livro daqui... Não me olhes assim, hem? - E para espantar o moleque atira aos seus pés o primeiro volume do Código Civil comentado. (JURANDIR:1995, p.161)
\end{abstract}

No episódio, os insultos, as humilhações e o objeto que lhe é arremessado revelam a falta de afetividade, o menosprezo e a violência vivenciada do cotidiano desse moleque, situações que se assemelham ao período da escravidão, quando negros, adultos e crianças, eram servos de seus senhores, que cometiam ofensas e afrontas como maneira de disciplinar e adestrar para as formas de trabalho. Sobre isso, José Roberto de Góes e Manolo Florentino relatam que "O adestramento da criança também se fazia pelo suplício. Não o espetaculoso das punições exemplares (reservadas aos pais), mas o suplício do dia a dia, feito de pequenas humilhações e grandes agravos." (GOÉS; FLORENTINO, 2000, p.185-186.)

Nesse caso, seu rebaixamento, iniciado pela sua animalização quando é comparado a um verme, projeta a vida desumana do menino e fornece um arquétipo para a sua identificação, ele não fala, não ouve, é apenas uns olhos, ou a ausência deles: "não tem mais olhos, seu vagabundinho?" (JURANDIR:1995, p.161). Tal sentimento manifesto por Dr. Campos se distancia daquele sentimento de paparicação, nas sociedades medievais, identificado por Ariés (2011), nas quais a proximidade das crianças com o mundo animal se estabelecia por se reconhecer sua fragilidade e imaturidade.

Notemos que as possibilidades do moleque sair dessa condição de desvalimento são, ainda, duplamente ironizadas pelo narrador, visto que quem lhe dispensa esses ultrajes é um Juiz de Direito, representante máximo da justiça local, justamente aquele que deveria atuar em prol das minorias. Por outro lado, o Código Civil, de nada serve para diminuir as desigualdades ou amparar as crianças como esse moleque, serve apenas para ser instrumento de violência contra ele.

Vale lembrar que, Tozoni-Reis (2002, p.12) quando se refere a infância na obra de José Lins do Rego, especialmente em Menino de Engenho, identificou que os filhos de trabalhadores eram sempre alcunhados de moleques, enquanto que os filhos das gentes de posse eram denominados de meninos. Essa circunstância também é observada nos romances dalcidianos, pois Eutanázio, Alfredo e Tales são continuamente chamados de meninos, em oposição àqueles mais pobres que são os moleques, delineando-se, de tal modo, dois núcleos de personagens infantis, entre os quais Alfredo assume uma função peculiar, pois inúmeras vezes expressa sua aversão aos moleques, a quem considera sujos, fedorentos e sem modos, entretanto, noutras vezes compartilha com eles das mesmas ações.

Por esse viés, podemos dizer que Alfredo, embora sempre considerado um menino, relacionado a um grupo social branco e "superior", ele também transita pelo universo dos moleques, negros e 
socialmente inferiorizados. Isto fica evidente em Chove nos Campos de Cachoeira, quando ele encontra Henrique, um dos poucos moleques que é nominado na narrativa:

Ainda ontem viu Henrique balar um passarinho que caiu na calçada da casa do Coronel Bernardo. Henrique riu, e apanhou o pobre morto e disse.

- Vou te comê de espeto.

- Se come então um passarinho desse?

— Se come. E no espeto. Não sabe o que é bom. Pra que tenho mea baladêra? Tu não gosta?

— Eu não.

- O que tu perde. És um branco...

— Tua boca é doce pra dizer isso... que sou um branco. Tu não vês minha cor? Alfredo não queria ser moreno mas se ofendia quando o chamavam de branco. Achava uma caçoada de moleque. (JURANDIR:1995, p.19)

Nessa passagem, observamos a percepção do moleque Henrique sobre Alfredo, bem como suas diferenças culturais. Alfredo acha estranho matar os passarinhos e comê-los, enquanto que para Henrique isto não é apenas uma brincadeira com baladeiras, é uma forma de saciar sua fome, uma necessidade que o filho de Major Alberto não devia ter, afinal, do seu ponto de vista, era um branco, um privilegiado. E, embora, Alfredo não se identifique assim, é a suposta superioridade que difere o menino do moleque.

Essa proposição fica ainda mais evidente, quando Alfredo se reporta a Tales e Jamilo, meninos que ele considera felizes, não somente porque não tem as pernas feridentas como as dele, mas, acima de tudo, por que figuram como as crianças ricas na narrativa, particularmente, Tales, que é muitas vezes referido no romance. Aliás, ele é a única criança que aparece com nome e sobrenome na narrativa: Tales de Mileto Gomes.

Tal distinção na composição da personagem assinala seu status social e sua linhagem como herdeiro de um rico fazendeiro do Marajó, o Dr. Gomes. Dessa maneira, Tales surge como um contraponto àqueles inominados e desvalidos, cuja a função se aproxima muitas vezes a de um antagonista, pois ele aparece como um rival para Alfredo, já que possui tudo o que ele gostaria de ter: "Sabe que Tales de Mileto embarca breve para o Instituto N. S. de Nazaré. Seu pai pode. Tem fazenda. Tales de Mileto tem fatos de gala branca, calcinha de casimira, sapatos de duas cores" (JURANDIR:1995, p.229), e mais, é o único menino em Cachoeira que tem chapéu, velocípede e ceia a meia-noite após a Missa do Galo, signos de sua riqueza material, que lhe possibilita diferenciar-se no vestir, no acesso ao brinquedo e nos hábitos alimentares.

Notamos também uma relativa adultização de Tales, que é sempre descrito como circunspecto e "encolarinhado" como o pai: "Nunca fez uma brincadeira. Não corre. Não ri. O Gomes proibiu a risada em sua casa. Ai de quem ri! Só a circunspecção! [...] é circunspecto como o pai." (JURANDIR, 1995, p 157). Tal seriedade e o comedimento nos modos demonstram um garoto também retirado de sua meninice para compor, desde os seus primeiros anos, um fazendeiro em miniatura, com ares de quem sabe que domina as relações sociais: "Tales de Mileto. Tem uma parte de olhar para os outros fazendo pouco, mostrando que tem dinheiro (JURANDIR, 1995, p.227-228)

Ao observar esses aspectos, vemos com mais nitidez a dimensão do projeto literário dalcidiano. Daí, ainda que o narrador dalcidiano promova a distinção de Tales na narrativa de Chove nos Campos de Cachoeira, tratando-o pelo nome e sobrenome, este não deixa de ser figura ridicularizada no romance. A começar pelo seu nome que faz referência direta ao filósofo, matemático e astrônomo da Grécia Antiga, Tales de Mileto, pois embora seu pai sempre esteja o elogiando e louvando suas qualidades, todos na Vila reconhecem a sua falta de inteligência: 
Gomes que tem um filho de onze anos, uma lesma, mas na mentalidade e na boca do pai, um gênio. Pois tem esse Gomes a paciência, o imbecil, de procurar pelos almanaques, quais foram os meninos precoces, etc. para comparar com o filho. $\mathrm{O}$ filho, que inteligência! Ora, todos sabem que Alfredo, filho do teu pai, é na verdade um menino muito inteligente e acho que está perdendo o seu tempo aqui. Pois o Gomes pega o seu filho, a lesma, um pequeno lombriguento e mudo, e diz que nem Alfredo se compara a ele. O pequeno nunca disse nada (JURANDIR:1995, p.156-157)

Alfredo, inclusive, diversas vezes questiona essa situação, afinal: "Por que Tales de Mileto, que é burro, vai logo para Belém e ele fica ali socado na escola de seu Proença?” (JURANDIR:1995, p.234). E como vingança, ou um modo de continuar resistindo ao seu desvalimento, Alfredo se põe a imaginar, a partir de seu carocinho mágico, circunstâncias vexatórias e humilhantes que Tales vivenciaria se fosse estudar em Belém:

[...]Tales de Mileto no Instituto N. S. de Nazaré. Quando o professor perguntasse:

— Sr. Tales, diga quem foi o primeiro regente do Brasil. - Tales baixava a e mordia o beiço, olhava os botões da blusa de cetim e mordia o beiço de novo, espiava para fora, batia com a caneta na carteira, como sempre fazia. Não, não sabes, Tales de Mileto Gomes? Pois eu sei. Volta para Cachoeira, Tales de Mileto Gomes, porque até o Zé Calazãs sabe mais depressa do que tu quais são os reinos da natureza. (JURANDIR:1995, p.260)

Dessa maneira, é no plano do imaginário que o caso se resolve, ou pelo menos se ameniza para o filho de d. Amélia, enquanto que no plano da realidade apesar de Alfredo possuir como trunfo a sua inteligência, fato notável no romance, ele percebe que isto não é suficiente. De qualquer modo, independente da falta de inteligência do filho de Dr. Gomes, a suposta superioridade de Alfredo se desfaz. Tales, assim, assume na economia do texto a função de redefinir a posição social de Alfredo, ou melhor dizendo, de afirmar a sua real posição social, pois através dele, embora o protagonista do ciclo Extremo-Norte tenha seus pequenos privilégios por ser filho do secretário da Intendência de Cachoeira, Alfredo é posto ao lado dos desvalidos, como se observa a partir do excerto abaixo:

Nessa mesma manhã vira o pai de Tales de Mileto comprar três quilos de carne e ele com o seu quilinho [...] Como se livrar daquele quilinho de carne? Os moleques sujos não podiam senão levar, e isso em grandes dias de fartura, meio quilo da pior carne para casa. Mas Alfredo não queria ver os moleques. Tinha uma certa vaidade quando os moleques olhavam, com olhar comprido, seu quilinho. Passava por eles com superioridade. Tudo isso porém se afundava com o desejo de partir para o colégio. (JURANDIR:1995, p, 259)

Assim, o menino Alfredo vai se dando conta de que nada adianta ser menino arguto, se não tem meios educacionais para desenvolver suas habilidades. Daí, não temos somente a revolta de Alfredo em ver Tales de Mileto seguir para o Colégio na capital paraense, na verdade, esse sentimento encobre o medo de que Tales se torne mais inteligente que ele, "Alfredo receia que Tales, indo para Belém, possa já saber mais do que ele, ficar mais inteligente, lhe deixar muito atrás" (JURANDIR:1995, p.228).

\section{A resistência dos moleques}

Vale apontar que nesse panorama recriado por Dalcídio Jurandir, os moleques encarnam o desvalimento social e cultural de crianças que estão à margem de uma infância digna. Isto, por sua vez, 
não significa que estes personagens mirins não reajam a esse sistema que opõe brancos e negros, ricos e pobres. Os pequenos furtos, por exemplo, são uma delas: "João Galinha, mais rapazola, tirava dinheiro da mesa do filtro, furtava o dinheiro que Major deixava para a carne." (JURANDIR:1995, p.209), afinal, tirar dos que tinham um pouco mais era uma maneira de realizar uma espécie de distribuição de renda.

Para além disso, os moleques nem sempre aceitam passivamente os ultrajes e as humilhações que lhe são dirigidas, há situações dentro do romance em que eles se revoltam e se vingam de seus algozes. Em um desses episódios, Eutanázio, quando criança, apedrejava cães, chicoteava carneiros, molestava galinhas, e batia nos garotos, que não lhe faziam nada porque era filho do respeitável Major Alberto. Contudo, quando ele empurra o peito do moleque Marcelo, a situação muda, pois: "O moleque não se fez esperar, a mão cantou em cheio na cara de Eutanázio que ficou atordoado. [...] Uma covardia o assaltou, fez ele sorrir para o moleque fingindo ter compreendido que aquilo não passara de brincadeira." (JURANDIR:1995, p.35).

Nesse trecho, a vingança é dada na mesma moeda, a bofetada é uma resposta aos maltratos físicos recebidos submissamente pelos moleques. Porém, Eutanázio, que figura uma classe dominadora, trata imediatamente de eliminar a seriedade do caso e lhe dar um contexto diferente, o de galhofa.

Em outra ocorrência, na narrativa, não há nenhum mascaramento da afronta, Alfredo é humilhado quando retorna da escola de seu Proença, justamente por alguém que o narrador chama de Bode e, ele mesmo considerava um bicho, já que "parecia um chimpanzé das gravuras de seu livro de História Natural" e "O riso dele era de macaco" (JURANDIR:1995, p.235).

Sobre ele, o narrador faz a seguinte descrição: "Era escuro, meio idiota, surdo. Sua voz era um regougo. Vestia roupas usadas, de casimira rota, era um Judas de sábado de aleluia. Mas metia medo". Tal exposição das suas características vão delineando o seu desvalimento, uma condição, que antes de tudo, causa temor em Alfredo. A vingança aqui se dá pelo rebaixamento do menino, Bode exige que ele tome "à benção" de joelhos:

\footnotetext{
— Ei, tome a bença, ei. Joelho!

$\mathrm{O}$ frio era mais intenso, o medo, a raiva do Bode, a certeza de que podiam ver, a humilhação. Era um momento de infinito desespero para Alfredo. [...] Com aquele frio e o medo, a necessidade de se livrar do monstro, Alfredo se ajoelhou, as pedras pareciam queimar-lhe os joelhos e tomou a bênção ao Bode. [...]. Alfredo saiu curvado, sumido no seu frio e na sua humilhação, era o resultado de não ir a Belém, de não ser ouvido por seu pai. [...], Bode era um bicho, Bode se desforrara em nome de todos os moleques maltratados por Alfredo. (JURANDIR: 1995, p.235)
}

Recordemos que o ato de tomar "à benção", é um ato de reconhecimento de autoridade e de demonstração de respeito, atitudes que são forçadamente exigidas de Alfredo, já que ele não lhes reconhece o valor. Vale acrescentar que se de um lado, temos o rebaixamento de Alfredo, por outro temos a elevação do Bode, pois ele deixa, ainda que apenas por alguns instantes, a sua posição de subalternidade, para dominar a situação, o que lhe poderia deixar a vontade para fazer outras exigências, no entanto, é ilustrativo que ele peça apenas reconhecimento e respeito.

\section{Considerações finais}

Nesse breve painel que expomos até aqui, é notável a relevância que a infância desvalida e os personagens mirins assumem na estrutura narrativa desse primeiro romance do Ciclo Extremo-Norte. E, ainda que, na ocasião da publicação da primeira edição de Chove nos campos de Cachoeira, seu projeto ético-literário ainda não tivesse se delineado por completo, é visível a sua opção por narrar 
uma Amazônia brasileira pela perspectiva dos mais pobres dessa região, emprestando, diversas vezes, a voz do narrador em terceira pessoa para contar de suas histórias, sonhos e humilhações.

Como se observa, entre os meninos e moleques construídos nessa narrativa, há uma luta de classes sendo encenada por esses personagens infantis. De um lado, o herdeiro dos Gomes, figurando uma elite minoritária e privilegiada, e. de outro, um filão de crianças pobres e que estão à margem da infância e de uma vida digna. Alfredo, por sua vez, surge como uma figura transitória, pois, embora, não se identifique como branco, rico e superior as outras crianças, fica claro que ele também não quer reconhecer suas raízes negras, sequer sua mestiçagem, fato que sucederá apenas nos romances seguintes a partir de um processo interior conflituoso.

Vale dizer, ainda, que isto tudo nos faz perceber a escolhas ideológicas de Dalcídio Jurandir, que fora comunista, filiado ao Partido Comunista Brasileiro, mas que soube dosar em sua escrita romanesca o seu ideário social, construindo, assim, uma narrativa que tece e promove muitos questionamentos, sem, contudo, se tornar panfletária.

\section{REFERÊNCIAS}

ARIÈS, Philippe. História Social da Criança e da Família. 2. ed. Rio de Janeiro: LCT, 2011

GOÉS, José Roberto de; FLORENTINO, Manolo. Crianças escravas, crianças dos escravos. In: DEL PRIORE, Mary (Org.). História das crianças no Brasil. 2. ed. São Paulo: Contexto, 2000. p. 185186.

JURANDIR, Dalcídio. Chove nos Campos de Cachoeira. Belém: CEJUP, 1997

JURANDIR, Dalcídio. Entrevista a Eneida de Moraes In: MORAES, Eneida. Romancistas também personagens. São Paulo: Cultrix, 1962

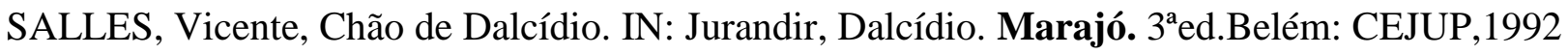

LEITE, Miriam L. Moreira. A infância no século XIX segundo memórias e livros de viagem. In: FREITAS. Marcos Cezar. (Org.). História Social da Infância no Brasil. São Paulo: Cortez, 1997

TOZONI-REIS, Marilia Freitas de Campos. Infância, escola e pobreza ficção e realidade. Campinas, SP: Autores associados, 2002. 